\title{
Time-Resolved UV-IR Experiments that Suggest Photoactivated Fe-Cu Dinuclear Catalyst
}

Kyle J. Clark, ${ }^{+}$Jacob T. Davis,,+ Doo-Hyun Kwon, ${ }^{*}$ Erin E. Martinez, Michael R. Talley, David J. Michaelis, * Daniel H. Ess, * and Matthew C. Asplund*

Department of Chemistry and Biochemistry, Brigham Young University, Provo, Utah 84602 USA 


\section{ABSTRACT}

Heterodinuclear complexes with a direct metal-metal bond offer the possibility of unique mechanisms and intermediates. The $\mathrm{Cp}(\mathrm{CO})_{2} \mathrm{Fe}-\mathrm{Cu}(\mathrm{IPr}) \quad(\mathrm{IPr}=$ N,N-bis(2,6diisopropylphenyl)imidazol-2-ylidene) heterodinuclear complex $\mathbf{1}$ is known to photochemically catalyze arene borylation. To examine possible initial steps of photo-initiated catalysis, we synthesized a triethylsilyl-substituted $\mathrm{Fe}-\mathrm{Cu}$ catalyst that provided cyclohexane solubility to conduct time-resolved UV-IR studies. Time-resolved vibrational spectroscopic measurements suggest that photolysis of $\mathbf{1}$ stimulates $\mathrm{CO}$ dissociation without $\mathrm{Fe}-\mathrm{Cu}$ metal-metal bond cleavage. This suggests that arene borylation catalysis may begin with a photochemical step rather than a relatively endothermic cleavage of the $\mathrm{Fe}-\mathrm{Cu}$ bond. A new possible catalytic cycle is proposed. 


\section{INTRODUCTION}

Compared to catalysts with a single metal and ligand framework, transition-metal heterodinuclear catalysts with a direct metal-metal bond offer the potential of unique mechanisms and intermediates, oxidation states, reactivity, and selectivity, especially for bond activation reactions (Scheme 1a). ${ }^{1}$ This divergent reactivity results from the ability of substrates to be activated across two metals and for organometallic mechanisms to occur over both metals (e.g. dinuclear oxidative addition). While heterodinuclear-mediated and catalyzed reactions were reported for classic transformations, such as alkene and ketone hydrogenation, ${ }^{2} \alpha$-olefin hydroformylation, ${ }^{3}$ ethylene polymerization, ${ }^{4}$ and olefin metathesis, ${ }^{5}$ recently there has been a large effort to exploit dinuclear catalyst for very challenging transformations. ${ }^{6,7,8,9,10}$ However, a major limitation to the further design and use of heterodinuclear catalysts is the identification of catalytic mechanisms. In many heterodinuclear-catalyzed reactions the mechanism responsible for unique reactivity and/or selectivity is unknown.

Mankad recently reported the photochemical catalytic arene borylation using the $\mathrm{Cp}(\mathrm{CO})_{2} \mathrm{Fe}-\mathrm{Cu}(\mathrm{IPr})$ heterodinuclear complex 1 (Scheme $1 \mathrm{~b} ; \quad(\mathrm{IPr}=$ N,N-bis(2,6diisopropylphenyl)imidazol-2-ylidene)). ${ }^{11}$ In this reaction with yields up to $70 \%$, the C-H bond of arenes, and the B-H bond of HBpin are activated and coupled, which for benzene results in phenylboronoic acid pinacol ester (PhBpin). Based on earlier work from Hartwig, ${ }^{12}$ the original mechanistic proposal involved thermal HBpin bond activation to generate the pair of mononuclear species (IPr)Cu-H and $\mathrm{Cp}(\mathrm{CO})_{2} \mathrm{Fe}-\mathrm{BPin}$ (Scheme 1c). Then, photo-promoted $\mathrm{CO}$ ejection leads to the mononuclear, coordinately unsaturated $\mathrm{Cp}(\mathrm{CO}) \mathrm{Fe}-\mathrm{BPin}$ intermediate that reacts with benzene to produce PhBpin. A ligand crossover experiment was performed as evidence of thermal/dark reactions for ligand exchange with complex 1. For example, mixing $(\mathrm{IPr}) \mathrm{CuFeCp} *(\mathrm{CO})_{2}$ with 
(IMes) $\mathrm{CuFeCp}(\mathrm{CO})_{2}$ (IMes = N,N'-bis(2,4,6-trimethylphenyl)imidazol-2-ylidene) results in $(\mathrm{IPr}) \mathrm{CuFeCp}(\mathrm{CO})_{2}$ and $(\mathrm{IMes}) \mathrm{CuFeCp} *(\mathrm{CO})_{2}$. However, this thermal crossover reaction required 48 hours to reach equilibrium and based on density functional theory (DFT) calculations Keith and Mankad proposed a direct bimolecular reaction that is likely unconnected to borylation catalysis. ${ }^{13}$

The initial steps of this catalytic process are intriguing for several reasons. The thermal B$\mathrm{H}$ bond activation across the $\mathrm{Fe}-\mathrm{Cu}$ bond leading to $(\mathrm{IPr}) \mathrm{Cu}-\mathrm{H}$ and $\mathrm{Cp}(\mathrm{CO})_{2} \mathrm{Fe}-\mathrm{BPin}$ mononuclear species requires a $\Delta H$ value of $>25 \mathrm{kcal} / \mathrm{mol}$. This suggests that there would be an extremely low concentration of the $\mathrm{Cp}(\mathrm{CO})_{2} \mathrm{Fe}-\mathrm{BPin}$ intermediate available for photoactivation and the quantum yield of these types of metal carbonyl complexes are relatively low. Alternatively, it could be possible that catalyst $\mathbf{1}$ undergoes $\mathrm{CO}$ photodissociation to initiate catalysis. However, this catalyst has a single $\mathrm{Fe}-\mathrm{Cu}$ metal-metal bond that could fragment upon irradiation rather than $\mathrm{CO}$ dissociation. CO photodissociation from 1 would give the monocarbonyl intermediate $(\mathrm{IPr}) \mathrm{CuFeCp}(\mathrm{CO})$, which could then undergo dinuclear $\mathrm{B}-\mathrm{H}$ activation and subsequent arene borylation. 
a)

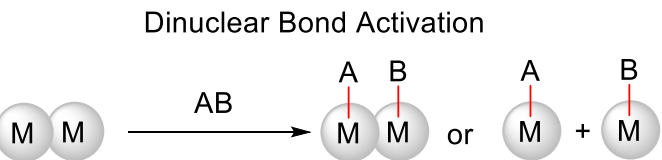

b)

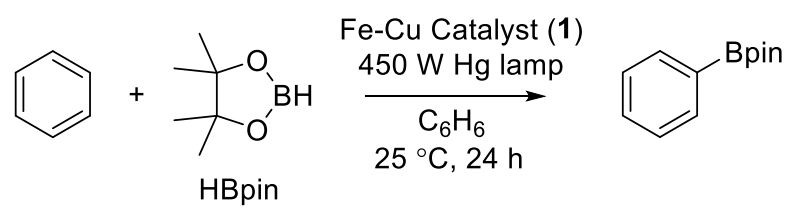

c)

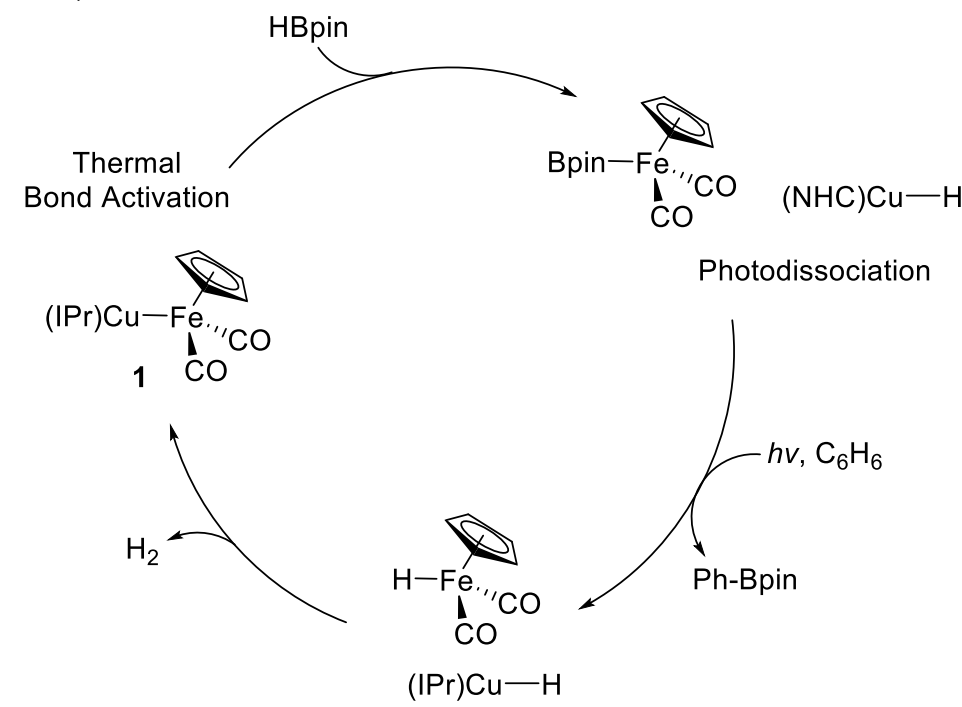

d)

EXAMINED IN THIS WORK $\begin{gathered}\text { Photochemically Activated } \\ \text { Catalytic Intermediate }\end{gathered}$

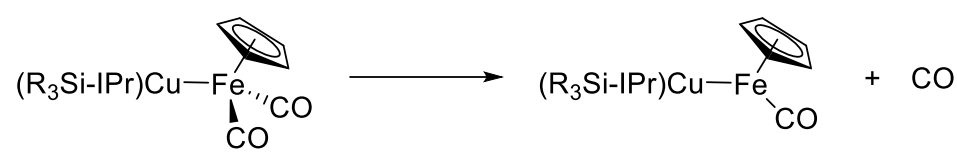

Scheme 1. a) Schematic view of bond activation reactions across a metal-metal bond of a heterodinuclear complex. b) Mankad's Fe-Cu photochemical heterodinuclear-catalyzed benzene borylation reaction. c) Previously proposed catalytic cycle involving dinuclear thermal (dark) B$\mathrm{H}$ bond activation, mononuclear $\mathrm{CO}$ photodissociation, and reformation of the $\mathrm{Fe}-\mathrm{Cu}$ catalyst $\mathbf{1}$. d) Alternative first catalytic step involving photodissociation of $\mathrm{CO}$ from $\mathbf{1}$ to generate a coordinatively unsaturated heterodinuclear intermediate. $\operatorname{IPr}=\operatorname{IPr}=$ N,N-bis(2,6diisopropylphenyl)imidazol-2-ylidene). 
One approach to examine the feasibility of heterodinuclear $\mathrm{CO}$ photodissociation to initiate catalysis is to use time-resolved vibrational spectroscopy to directly detect a the monocarbonyl (IPr) $\mathrm{CuFeCp}(\mathrm{CO})$ intermediate. ${ }^{14}$ In this work we report the synthesis and X-ray characterization of a triethylsilyl-substituted $\mathrm{Fe}-\mathrm{Cu}$ catalyst that provided cyclohexane solubility to conduct timeresolved UV/IR studies. We also present time-resolved vibrational spectroscopic measurements that show that photolysis of the catalysis with UV light suggests that CO photodissociation from the $\mathbf{1}$ is plausible without metal-metal bond cleavage (Scheme 1d). Overall, this provides the ability to propose a catalytic cycle for photocatalytic arene borylation.

\section{RESULTS AND DISCUSSION}

To identify the initial photo-generated intermediates, microsecond step-scan FTIR measurements of the $\mathrm{CO}$ vibrational spectrum was performed using catalyst $\mathbf{1}$. However, initial UV/IR experiments in benzene solvent showed overlap of the Fe-CO modes with vibrational modes in the solvent. Alkane solvents have no absorbances in the metal-CO region of the spectrum, but the dinuclear catalyst $\mathbf{1}$ is not soluble in the alkane at high enough concentrations to allow measurement of the vibrational spectrum. To address this limitation, we synthesized a silylsubstituted version of the $\mathrm{Fe}-\mathrm{Cu}$ complex (5, Scheme 2) that provided significant solubility in cyclohexane, and the silyl-appended catalyst is competent for borylation. ${ }^{11}$

The synthesis of complex $\mathbf{5}$ began with protection of commercially available imidazolium ligand 2 with borane at the 2-position. Next, deprotonation of the imidazole with $n$-butyl lithium followed by quenching with chlorotriethylsilane provided silylated imidazole 3 . The borane group was then removed by treatment with triflic acid and methanol and the corresponding imidazolium 
salt was exposed to sodium tert-butoxide and $\mathrm{CuCl}$ to provide the desired copper(I) carbene complex 4. To finish the synthesis, complex 4 was treated with anionic potassium cyclopentadienyldicarbonylferrate (KFp) to provide the final heterobimetallic complex $\mathbf{5}$ in $\mathbf{7 9 \%}$ yield. X-ray quality single crystals of complex 2 were grown via vapor deposition with hexanes and toluene and the X-ray crystal structure is shown in Scheme 2b. Importantly, while the addition of the triethylsilane imparted solubility in cyclohexane, it did not significantly impact the bonding of the Fe-Cu complex. For example, the $\mathrm{Fe}-\mathrm{Cu}$ distance in $\mathbf{5}$ is $2.349 \AA$, which is nearly identical to $\mathbf{1}(2.346 \AA) .{ }^{15}$

a)
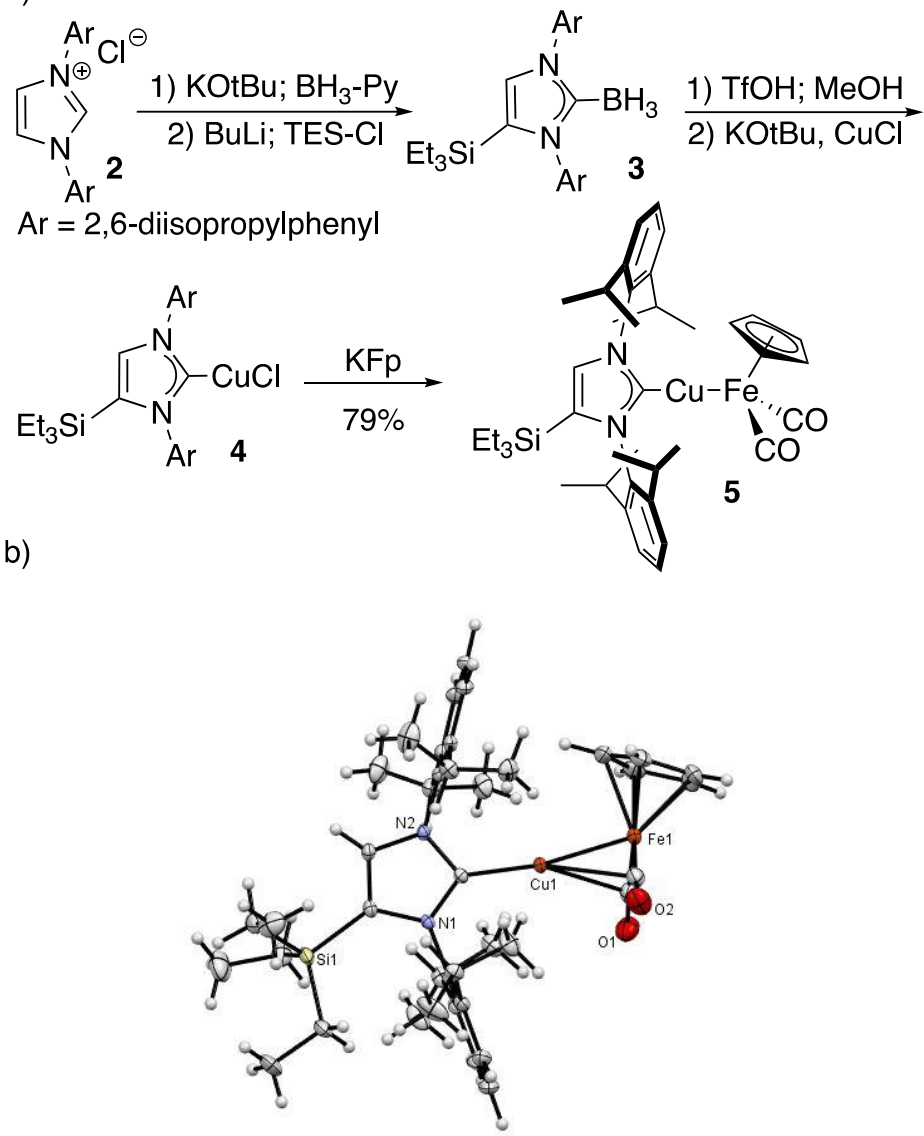

Scheme 2. a) Synthetic scheme for the triethylsilyl-substituted Fe-Cu complex 5. b) X-ray structure of 5 . 
With a cyclohexane soluble version of the $\mathrm{Fe}-\mathrm{Cu}$ catalyst synthesized, we proceeded with UV-IR and time-resolved FTIR experiments. Alkane solutions are typically viewed as weakly coordinating solvents, but can induce caging effects. ${ }^{16}$ Spectroscopic measurements were performed using a modified Bruker IFS-66 FTIR spectrometer in step scan mode. The detector was a small area MCT with a rise time of $10 \mathrm{~ns}$, and an optical filter which limited the signal to the region from $1400-2150 \mathrm{~cm}^{-1}$. The internal 14-bit digitizer was used, yielding spectra every 5 microseconds, with a resolution of $4 \mathrm{~cm}^{-1}$. UV light for excitation was from a Continuum YAG, with frequency tripling optics which yielded $9 \mathrm{~ns}$ pulses at $355 \mathrm{~nm}$, and pulse energies were kept less than $5 \mathrm{~mJ}$ to minimize sample degradation, and thermal effects. This wavelength was selected because complex $\mathrm{b}$ has a broad absorption band in the UV from 300-400 $\mathrm{nm}$ (see supporting information), and so the $355 \mathrm{~nm}$ laser light will excite the complex to the same excited electronic state as the mercury lamp used by Mankad. Samples were $3 \mathrm{mM}$ in concentration and were purged with nitrogen gas to keep them air and water free.

The blue plot in Figure 1 shows an initial FTIR spectrum after UV excitation for a solution containing complex 5. The two Fe-CO stretches for the initial dicarbonyl dinuclear complex at 1869 and $1925 \mathrm{~cm}^{-1}$, show a decrease in absorbance after excitation. In addition to the disappearance of these peaks we found a new positive peak indicative of a monocarbonyl $\mathrm{Fe}-\mathrm{CO}$ stretch that occurs at $1888 \mathrm{~cm}^{-1}$. Importantly, the disappearance of the two peaks and formation of a new peak indeed suggests $\mathrm{CO}$ photodissociation from $\mathbf{5}$ to generate a coordinatively unsaturated $\left(\mathrm{Et}_{3} \mathrm{Si}-\mathrm{IPr}\right) \mathrm{CuFeCp}(\mathrm{CO})$ intermediate, rather than breaking of the $\mathrm{Fe}-\mathrm{Cu}$ bond, which would have shown two new $\mathrm{CO}$ absorbances. Consistent with these measurements, M06- $\mathrm{L}^{17} / 6-$ $31 \mathrm{G}^{* *}$ [LANL2DZ] (chosen because of the first-row transition metals) DFT calculations in cyclohexane solvent gave antisymmetric and symmetric CO stretches for 5 at 1857 and $1907 \mathrm{~cm}^{-}$ 
${ }^{1}$ (scaled using a 0.952 factor). ${ }^{18} \mathrm{The}\left(\mathrm{Et}_{3} \mathrm{Si}-\mathrm{IPr}\right) \mathrm{CuFeCp}(\mathrm{CO})$ structure gave a stretch at $1818 \mathrm{~cm}^{-}$

${ }^{1}$. In all structures the $\mathrm{CO}$ stretching values are slightly red shifted.

Unfortunately, complex $\mathbf{5}$ showed a very low quantum yield for CO photodissociation that could be due internal conversion to the electronic ground state, and non-radiative cooling. This somewhat complicated the IR spectrum because trace amounts of a highly photoactive $\mathrm{Cp}_{2} \mathrm{Fe}_{2}(\mathrm{CO})_{4}(6)$ led to significant absorbances in the IR spectra at 1792, 1822, 1933, and 1960 $\mathrm{cm}^{-1}$. To confirm these peaks are due to $\mathbf{6}$, the overlaid red plot in Figure 1 shows an IR spectrum of a solution containing only 6 after UV excitation. The overlap between the red and the blue spectra is very close and shows that none of the peaks between 1865 and $1925 \mathrm{~cm}^{-1}$ arise from 6 . DFT calculations of $\mathrm{Cp}_{2} \mathrm{Fe}_{2}(\mathrm{CO})_{4}$ gave stretches at 1803 and $1940 \mathrm{~cm}^{-1}$, which is consistent with red and blue shift of absorbances away form the absorbances for complex $\mathbf{5}$.

Importantly, the presence of $\mathbf{6}$ can be detected prior to UV light photolysis, which indicates that while the NMR is relatively absent of unwanted side products a minor amount of $\mathbf{6}$ could not be removed. Indeed, it is well known that metal-metal bond fragmentation is well known to be competitive with CO photodissociation..$^{14}$ For example, for $(\mathrm{CO})_{5} \mathrm{M}-\mathrm{M}(\mathrm{CO})_{5}$ type species that there can be competition between metal-metal bond homolysis, dissociation of $\mathrm{CO}$, and nondissociative relaxation, ${ }^{19}$ and these routes are generally heavily influenced by excitation wavelength. ${ }^{20}$ While we cannot completely rule out that a minor amount of $\mathrm{Cp}_{2} \mathrm{Fe}_{2}(\mathrm{CO})_{4}$ is formed under UV light exposure due to $\mathrm{Fe}-\mathrm{Cu}$ metal fragmentation, ${ }^{21}$ this is less likely since this compound is present prior to photolysis. Additionally, we do not see new $\mathrm{CpFe}(\mathrm{CO})_{2}$ absorbances in time-resolved studies (see below). 


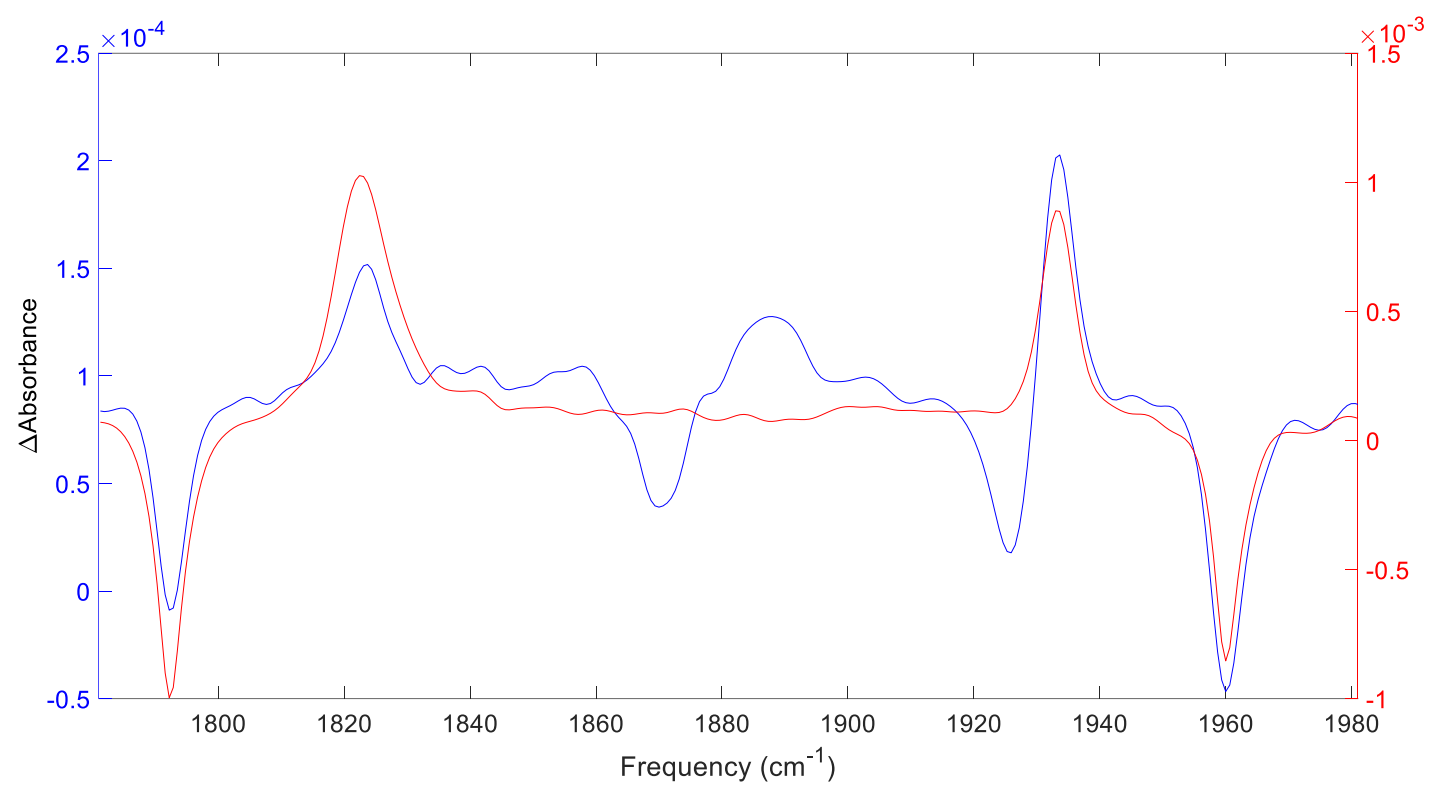

Figure 1. Plot of IR frequency versus absorbance. Blue: Change in IR absorbance of complex 5 after UV pulses at $355 \mathrm{~nm}$. Red: Change in IR absorbance of $\mathrm{Cp}_{2} \mathrm{Fe}_{2}(\mathrm{CO})_{4}$ after UV pulses at 355 nm.

Our assignment of a dicarbonyl to monocarbonyl change upon exposure to UV light is consistent with many previous reports for mononuclear or homodinuclear complexes. For example, as a comparison to our measured values, (acac) $\operatorname{Rh}(\mathrm{CO})_{2}$ in cyclohexane showed dicarbonyl stretches at 2082 and $2013 \mathrm{~cm}^{-1}$ and then the monocarbonyl showed a single stretch at $1996 \mathrm{~cm}^{-1} .{ }^{22}$ For this $(\mathrm{acac}) \mathrm{Rh}(\mathrm{CO})_{2}$ complex, the transient bleaches at the CO stretch frequencies were recovered at about $40 \mathrm{ps}$ time. Also related, Lees showed that $\mathrm{CpRh}(\mathrm{CO})_{2}$ in decalin with 313 and $458 \mathrm{~nm}$ light that the monocarbonyl can be trapped with triphenylphosphine. ${ }^{23}$ For this complex the bleaching of dicarbonyl CO bands occurred at 2046 and $1982 \mathrm{~cm}^{-1}$ with concurrent new monocarbonyl peak at $1954 \mathrm{~cm}^{-1}$ for the phosphine bound structure. Harris also examined several dicarbonyl $\mathrm{Cp}$-metal complexes. For example, triplet $\mathrm{CpCo}(\mathrm{CO})_{2}$ in a heptane shows a monocarbonyl at $1990 \mathrm{~cm}^{-1}$ and remains for about $660 \mathrm{ps}^{.24,25}$ While a tricarbonyl, but related to borylation reactions, Hartwig, Webster, and Harris reported nanosecond and microsecond IR for 
$\mathrm{Cp} * \mathrm{~W}(\mathrm{CO})_{3}(\mathrm{Bpin})$. In pentane, UV-IR analysis showed bleaches at 1899, 1914, and $2000 \mathrm{~cm}^{-1} \cdot{ }^{26}$ These peaks changed on the $30-200$ ps time scale. In addition to these bleaches there was also peaks from W-BPin fragmentation with very fast recombination and the growth of a $\mathrm{Cp}^{*} \mathrm{~W}(\mathrm{CO})_{3}($ pentane) complex, which can be seen on the nanosecond and microsecond time scales.

We next examined time-resolved changes in the IR spectrum of $\mathbf{5}$. Figure 2 shows snapshots of the evolution of the absorbance peaks over $85 \mu$ s. At $25 \mu$ s after UV excitation the two negative peaks at 1868 and $1925 \mathrm{~cm}^{-1}$ have fully formed. However, the two negative peaks are not long lasting. These peaks slowly decrease over time, likely due to $\mathrm{CO}$ recombination. At $85 \mu$ s while these two negative peaks are still clearly visible, they are substantially decreasing. The positive peak at $1885 \mathrm{~cm}^{-1}$ is completely gone by $85 \mu$ s. This indicates that when $\mathbf{5}$ is not in the presence of the reaction partners, such as HBPin and benzene, the activated catalyst likely only remains in the active form for a short time. However, under catalytic conditions ( $\mathrm{Et}_{3} \mathrm{Si}_{-}$ $\mathrm{IPr}) \mathrm{CuFeCp}(\mathrm{CO})$ likely persists for substantially longer time through coordination with reaction substrates. 

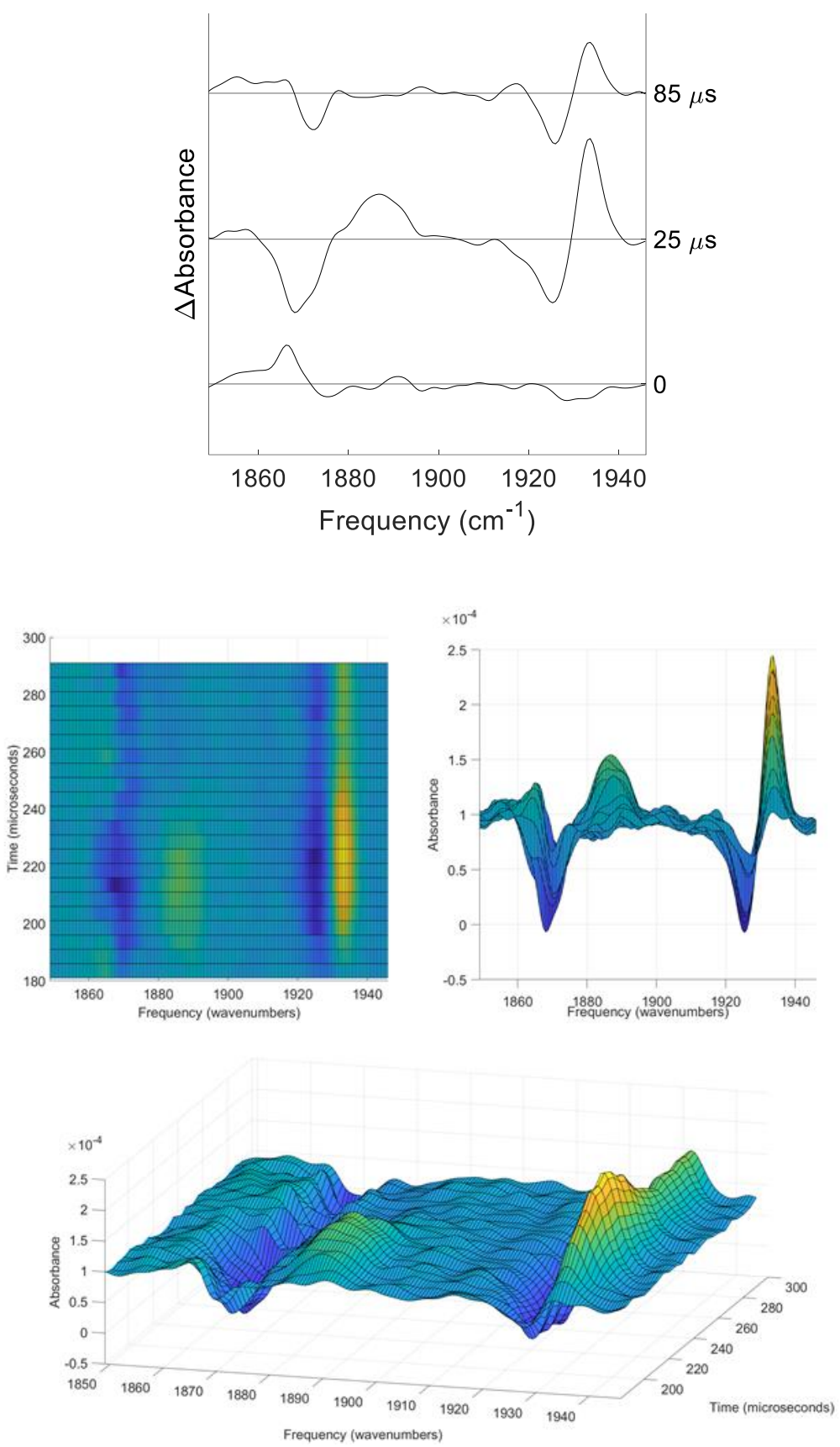

Figure 2. Top: Change in absorbance spectrum of $\mathbf{5}$ before UV laser excitation, $25 \mu$ s after excitation, and $85 \mu \mathrm{s}$ after excitation. Bottom: Several multidimensional plots of change in absorbance after laser exposure.

With the static and time-resolved IR information, it is now possible to propose an alternative catalytic cycle. Scheme 3 shows that UV-induced CO dissociation results in conversion 
of heterodinuclear $\mathbf{5}$ (or $\mathbf{1}$ ) to the corresponding dinuclear monocarbonyl intermediate $\mathbf{7}$. After $\mathbf{7}$ is formed, while not directly tied to the current UV-IR studies, it is likely that this complex 7 is thermally reactive towards HBpin and can undergo B-H addition across the $\mathrm{Fe}-\mathrm{Cu}$ metal-metal bond to generate $(\mathrm{NHC}) \mathrm{Cu}-\mathrm{H}$ and $\mathrm{Cp}(\mathrm{CO}) \mathrm{Fe}-\mathrm{BPin}$. The remainder of the catalytic cycle is similar to Mankad and Keith's proposal where the Fe-BPin complex can react with benzene to generate the $\mathrm{Ph}-\mathrm{Bpin}$ and reformation of the dinuclear complex generates $\mathrm{H}_{2}$.

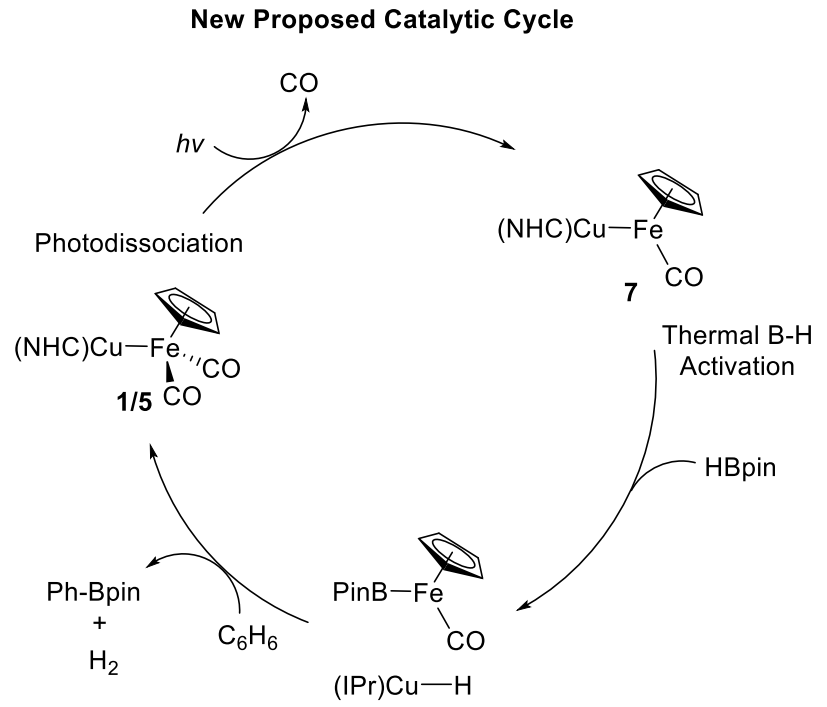

Scheme 3. Revised catalytic cycle based on UV-IR examination of heterodinuclear complex 5.

\section{CONCLUSIONS}

In this work we examined the possibility of photocatalysis being initialized through UVinduced $\mathrm{CO}$ photodissociation from an $\mathrm{Fe}-\mathrm{Cu}$ dinuclear catalyst. To accomplish this, we synthesized a new silylated, alkane-soluble Fe-Cu complex. Static and time-resolved IR after UV laser excitation showed that the $\mathrm{Fe}-\mathrm{Cu}$ metal-metal bond remains intact and that $\mathrm{CO}$ dissociation occurs. This suggests that catalysis begins with a $\mathrm{CO}$ photodissociation rather than thermal B-H bond activation as previously proposed. While the lifetime of intermediate 7 is likely on the $\mu$ s 
time scale or less, this is still long enough to undergo subsequent thermal reactions. However, from this work it was clear that this dinuclear complex has a very low quantum yield of photodissociation of CO. Therefore, further in-depth studies will be required to directly detect dinuclear and mononuclear intermediates for reaction between the photoactivated $\left(\mathrm{Et}_{3} \mathrm{Si}-\right.$ $\operatorname{IPr}) \mathrm{CuFeCp}(\mathrm{CO})$ intermediate and HBPin and benzene. This work does not provide direct comparison of possible rates for reaction between the dinuclear photogenerated monocarbonyl with substrates versus thermal generated mononuclear complexes and photoactivation.

\section{ASSOCIATED CONTENT}

Supporting Information. Experimental details and procedures. The Supporting Information is available free of charge on the ACS Publications website.

\section{AUTHOR INFORMATION}

\section{Corresponding Author}

*dhe@chem.byu.edu, asplund@chem.byu.edu,dmichaelis@chem.byu.edu

\section{Author Contributions}

"These authors contributed equally. K.J.C. assisted in synthesis, performed UV/IR studies, and computed vibrational frequencies. J.T.D. performed UV/IR studies. D-H.K. initiated synthesis and UV/IR studies. E.E.M. and M.R.T. completed synthesis. D.J.M. direct synthesis work, interpreted data, and edited the manuscript. M.C.A. directed UV/IR studies, interpreted data, and edited the 
manuscript. D.H.E conceived of the project, directed research, interpreted data, and wrote and edited the manuscript.

\section{Funding Sources}

D.H.E. thanks the National Science Foundation Chemical Catalysis Program for support (CHE1764194). D.J.M thanks the Chemical Synthesis Program of the National Science Foundation for support (CHE-1665015).

\section{ACKNOWLEDGEMENT}

We thank BYU Department of Chemistry and Biochemistry and College of Physical and Mathematical Sciences for facilities.

\section{REFERENCES}

1. a) Sinfelt, J. H. Bimetallic Catalysts: Discoveries, Concepts and Applications; John Wiley and Sons: New York, 1983. b) Bullock, R. M.; Casey, C. P. Heterobimetallic Compounds Linked by Heterodifunctional Ligands. Acc. Chem. Res. 1987, 20, 167-173. c) Zanello, P.; Tamburini, S.; Alessandro Vigato, P.; Antonio Mazzocchin, G. Synthesis, Structure and Electrochemical Characterization of Homo- and Heterodinuclear Copper Complexes with Compartmental Ligands. Coord. Chem. Rev. 1987, 77, 165-273. d) Stephan, D. W. Early-late Heterobimetallics. Coord. Chem. Rev. 1989, 95, 41-107. e) Beuken, E. K. van den; Feringa, B. L. Bimetallic Catalysis by Late Transition Metal Complexes. Tetrahedron 1998, 54, 12985-13011. f) Wheatley, N.; Kalck, 
P. Structure and Reactivity of Early-Late Heterobimetallic Complexes. Chem. Rev. 1999, 99, 3379-3419. g) Gade, L. H. Highly Polar Metal-Metal Bonds in "Early-Late" Heterobimetallic Complexes. Angew. Chem. Int. Ed. 2000, 39, 2658-2678. h) Oro, L. A.; Sola, E. Mechanistic Aspects of Dihydrogen Activation and Catalysis by Dinuclear Complexes in Recent Advances in Hydride Chemistry, Elsevier, 2001, 299-327.

2. Hostetler, M. J.; Bergman, R. G. Synthesis and Reactivity of Cp Synthesis and Reactivity of $\mathrm{Cp}_{2} \mathrm{Ta}\left(\mathrm{CH}_{2}\right)_{2} \operatorname{Ir}(\mathrm{CO})_{2}$ : an Early-late Heterobimetallic Complex that Catalytically Hydrogenates, Isomerizes and Hydrosilates Alkenes. J. Am. Chem. Soc. 1990, 112, 8621-8623.

3. a) Gelimini, L.; Stephan, D. W. Preparation, Reactivity, Hydroformylation Catalysis, and Structural Studies of the Early Transition Metal/Late Transition Metal Heterobimetallic Complexes $\mathrm{Cp}_{2} \mathrm{M}\left(\mu-\mathrm{PR}_{2}\right)_{2} \mathrm{M}^{\prime} \mathrm{H}(\mathrm{CO}) \mathrm{PPh}_{3}\left(\mathrm{M}=\mathrm{Zr}\right.$, Hf; $\left.\mathrm{M}^{\prime}=\mathrm{Rh}, \mathrm{Ir}\right)$. Organometallics, 1988, 7 , 849-855. b) Rida, M. A.; Smith, A. K. A Bimetallic Hydroformylation Catalyst: High Regioselectivity through Heterobimetallic Cooperativity. J. Mol. Catal. A: Chem. 2003, 202, 8795. c) Dickson, R. S.; De Simone, T.; Campi, E. M.; Jackson, W. R. Hydroformylation of Alkenes and Alkynes using a Heterobinuclear Rh-W Catalyst. Inorg. Chim. Acta 1994, 220, 187-192.

4. a) Lindenberg, F.; Shribman, T.; Sieler, J.; Hey-Hawkins, E.; Eisen, M. Dinuclear Phosphidoand Arsenido Early/Late Transition Metal Complexes. Efficient Catalysts for Ethylene Polymerization. J. Organomet. Chem. 1996, 515, 19-25. b) Motta, A.; Fragalà, I. L.; Marks, T. J. Proximity and Cooperativity Effects in Binuclear d Olefin Polymerization Catalysis. Theoretical Analysis of Structure and Reaction Mechanism. J. Am. Chem. Soc. 2009, 131, 3974-3984. c) Yan, X.; Chernega, A.; Green, M. L. H.; Sander, J.; Souter, J.; Ushioda, T. Homo- and Hetero-binuclear Ansa-metallocenes of the Group 4 Transition Metals as Homogeneous Co-catalysts for the Polymerization of Ethane and Propene. J. Mol. Catal. A: Chem. 1998, 128, 119-141. 
5. a) Ozawa, F.; Park, J. W.; Mackenzie, P. B.; Schaefer, W. P.; Henling, L. M.; Grubbs, R. H. Structure and Reactivity of Titanium-Platinum and -Palladium Heterobinuclear Complexes $\mu$ Methylene Ligands. J. Am. Chem. Soc. 1989, 111, 1319-1327. b) Dias, E. L.; Grubbs, R. H. Synthesis and Investigation of Homo- and Heterobimetallic Ruthenium Olefin Metathesis Catalysts Exhibiting Increased Activities. Organometallics 1998, 17, 2758-2767.

6. a) Thomas, C. M. Metal-metal Multiple Bonds in Early/Late Heterobimetallic Complexes: Applications Toward Small Molecule Activation and Catalysis. Comments on Inorganic Chemistry 2011, 32, 14. b) Cooper, B. G.; Napoline, J. W.; Thomas, C. M. Catalytic Applications of Early/Late Heterobimetallic Complexes Catal. Rev. 2012, 54, 1-40.

7. a) Mankad, N. P. Selectivity Effects in Bimetallic Catalysis. Chem. Eur. J. 2016, 22, 5822-5829.

b) Powers, I. G.; Uyeda, C. Metal-Metal Bonds in Catalysis. ACS Catal. 2017, 7, 936-958.

8. a) Buchwalter, P.; Rose, J.; Braunstein, P. Multimetallic Catalysis Based on Heterometallic Complexes and Clusters. Chem. Rev. 2015, 115, 28-126. b) Ed. Kalck, P.; Homo- and Heterobimetallic Complexes in Catalysis: Cooperative Catalysis Topics in Organometallic Chemistry, Vol. 59, 2016, Springer. c) Ritleng, V.; Chetcuti, M. J. Hydrocarbyl Ligand Transformations on Heterobimetallic Complexes. Chem. Rev. 2007, 107, 797-858. d) Maggini, S. Classification of P,N-binucleating Ligands for Hetero- and Homobimetallic Complexes. Coordination Chem. Rev. 2009, 253, 1793-1832. e) Vlugt, J. I. van der Cooperative Catalysis with First-Row Late Transition Metals. Eur. J. Inorg. Chem. 2012, 363-375. f) Bratko, I.; Gómez, M. Polymetallic complexes linked to a single-frame ligand: cooperative effects in catalysis. Dalton Trans. 2013, 42, 10664-10681. 
9. Cammarota, R. C.; Vollmer, M. V.; Xie, J.; Ye, J.; Linehan, J. C.; Burgess, S. A.; Appel, A. M.; Gagliardi, L.; Lu, C. C. A bimetallic Nickel-Gallium Complex Catalyzes $\mathrm{CO}_{2}$ Hydrogenation via the Intermediacy of an Anionic d ${ }^{10}$ Nickel Hydride. J. Am. Chem. Soc. 2017, 139, 14244-14250.

10. Siedschlag, R. B.; Bernales, V.; Vogiatzis, K. D.; Planas, N.; Clouston, L. J.; Bill, E.; Gagliardi, L.; Lu, C. C. Catalytic Silylation of Dinitrogen with a Dicobalt Complex. J. Am. Chem. Soc. 2015, $137,4638-4641$.

11. a) Mazzacano, T. J.; Mankad, N. P. Base Metal Catalysts for Photochemical C-H Borylation That Utilize Metal-Metal Cooperativity. J. Am. Chem. Soc. 2013, 135, 17258-17261. b) Leon, N. J.; Yu, H.-C.; Mazzacano, T. J.; Mankad, N. P. Pursuit of C-H Borylation Reactions with NonPrecious Heterobimetallic Catalysts: Hypothesis-Driven Variations on a Design Theme. Synlett 2020, 31, 125-132.

12. Waltz, K. M.; Hartwig, J. F. Functionalization of Alkanes by Isolated Transition Metal Boryl Complexes. J. Am. Chem. Soc. 2000, 122, 11358-11369.

13. Parmelee, S. R.; Mazzacano, T. J.; Zhu, Y.; Mankad, N. A.; Keith, J. A. A Heterobimetallic Mechanism for C-H Borylation Elucidated from Experimental and Computational Data. ACS Catal. 2015, 5, 3689-3699.

14. Perutz, R. N.; Torres, O.; Viček Jr., A. Photochemistry of Metal Carbonyls. Comprehensive Inorganic Chemistry II. 229-253.

15. Jayarathne, U.; Mazzacano, T. J.; Bagherzadeh, S.; Mankad, N. P. Heterobimetallic Complexes with Polar, Unsupported $\mathrm{Cu}-\mathrm{Fe}$ and $\mathrm{Zn}-\mathrm{Fe}$ Bonds Stabilized by N-Heterocyclic Carbenes. Organometallics 2013, 32, 3986-3992.

16. Yang, H.; Snee, P. T. Kotz, K.; Payne, C. K.; Harris, C. B. Femtosecond Infrared Study of the Dynamics of Solvation and Solvent Caging. J. Am. Chem. Soc. 2001, 123, 4204-4210. 
17. a) Structures were optimized with the SMD cyclohexane model in Gaussian 16. b) Gaussian 16, Revision B.01, Frisch, M. J.; Trucks, G. W.; Schlegel, H. B.; Scuseria, G. E.; Robb, M. A.; Cheeseman, J. R.; Scalmani, G.; Barone, V.; Petersson, G. A.; Nakatsuji, H.; Li, X.; Caricato, M.; Marenich, A. V.; Bloino, J.; Janesko, B. G.; Gomperts, R.; Mennucci, B.; Hratchian, H. P.; Ortiz, J. V.; Izmaylov, A. F.; Sonnenberg, J. L.; Williams-Young, D.; Ding, F.; Lipparini, F.; Egidi, F.; Goings, J.; Peng, B.; Petrone, A.; Henderson, T.; Ranasinghe, D.; Zakrzewski, V. G.; Gao, J.; Rega, N.; Zheng, G.; Liang, W.; Hada, M.; Ehara, M.; Toyota, K.; Fukuda, R.; Hasegawa, J.; Ishida, M.; Nakajima, T.; Honda, Y.; Kitao, O.; Nakai, H.; Vreven, T.; Throssell, K.; Montgomery, J. A., Jr.; Peralta, J. E.; Ogliaro, F.; Bearpark, M. J.; Heyd, J. J.; Brothers, E. N.; Kudin, K. N.; Staroverov, V. N.; Keith, T. A.; Kobayashi, R.; Normand, J.; Raghavachari, K.; Rendell, A. P.; Burant, J. C.; Iyengar, S. S.; Tomasi, J.; Cossi, M.; Millam, J. M.; Klene, M.; Adamo, C.; Cammi, R.; Ochterski, J. W.; Martin, R. L.; Morokuma, K.; Farkas, O.; Foresman, J. B.; Fox, D. J. Gaussian, Inc., Wallingford CT, 2016. c) Zhao, Y.; Truhlar, D. G. The M06 Suite of Density Functionals for Main Group Thermochemistry, Thermochemical Kinetics, Noncovalent Interactions, Excited States, and Transition Elements: Two New Functionals and Systematic Testing of Four M06-Class Functionals and 12 Other Functionals. Theor. Chem. Acc. 2008, 120, $215-241$.

18. Kanchanakungwankul, S.; Bao, J. L.; Zheng, J.; Alecu, I. M.; Lynch, B. J.; Zhao, Y.; Truhlar D. G. Database of Frequency Scale Factors for Electronic Model Chemistries - Version 4. https://comp.chem.umn.edu/freqscale/. Accessed 1/1/2021.

19. a) Meyer, T. J.; Caspar, J. V. Photochemistry of metal-metal bonds. Chem. Rev. 1985, 85, 187218. b) Wrighton, M.; Bredesen, D. Symmetrical cleavage of the metal-metal bond in decacarbonyldirhenium (0) by ultraviolet irradiation. J. Organomet. Chem. 1973, 50, C35-C38. c) 
Wegman, R. W.; Olsen, R. J.; Gard, D. R.; Faulkner, L. R.; Brown, T. L. Flash photolysis study of the metal-metal bond homolysis in dimanganese decacarbonyl and dirhenium decacarbonyl. $J$. Am. Chem. Soc. 1981, 103, 6089-6092. d) Firth, S.; Hodges, P. M.; Poliakoff, M.; Turner, J. J.; Therien, M. J. Selective loss of $\mathrm{CO}$ in the photochemistry of $\operatorname{MnRe}(\mathrm{CO})_{10}$ : a study using matrix isolation and time-resolved infrared spectroscopyl. J. Organomet. Chem. 1987, 331, 347-355.

20. a) Wrighton, M. S.; Ginley, D. S. Photochemistry of metal-metal bonded complexes. II. Photochemistry of rhenium and manganese carbonyl complexes containing a metal-metal bond. $J$. Am. Chem. Soc. 1975, 97, 2065-2072. b) Gard, D. R.; Brown, T. L. Photochemical reactions of dirhenium decacarbonyl with water. J. Am. Chem. Soc. 1982, 104, 6340-6347. c) Kobayashi, T.; Ohtani, H.; Noda, H.; Teratani, S.; Yamazaki, H.; Yasufuku, K. Excitation wavelength dependence of photodissociation and the secondary laser pulse photolysis of dimanganese decacarbonyl. Organometallics 1986, 5, 110-113. d) Seder, T. A.; Church, S. P.; Weitz, E. Photodissociation pathways and recombination kinetics for gas-phase dimanganese decacarbonyl. J. Am. Chem. Soc. 1986, 108, 7518-7524.

21. Boulanger, S. A.; Zhu, L.; Tang, L.; Saha, S.; Keszler, D. A.; Fang, C. Photoinduced Charge Transfer and Bimetallic Bond Dissociation of a Bi-W Complex in Solution. J. Phys. Chem. Lett. 2020, $11,7575-7582$.

22. Dougherty, T. P.; Grubbs, W. T.; Heilweil, E. J. Photochemistry of Rh(CO) $)_{2}$ (acetylacetonate) and related metal dicarbonyls studied by ultrafast infrared spectroscopy. J. Phys. Chem. 1994, 98, 9396-9399.

23. Drolet, D. P.; Less, A. J. Solution photochemistry of $\left(\eta^{5}-\mathrm{C}_{5} \mathrm{R}_{5}\right) \mathrm{Rh}(\mathrm{CO})_{2}(\mathrm{R}=\mathrm{H}, \mathrm{Me})$ complexes: pathways for photosubstitution and $\mathrm{C}-\mathrm{H} / \mathrm{Si}-\mathrm{H}$ bond activation reactions. J. Am. Chem. Soc. 1992, 114, 4186-4194. 
24. Snee, P. T.; Payne, C. K.; Kotz, K. T.; Yang, H.; Harris, C. B. Triplet organometallic reactivity under ambient conditions: an ultrafast UV pump/IR probe study. J. Am. Chem. Soc. 2001, 123, 2255-2264.

25. Lomont, J. P.; Nguyen, S. C.; Schlegel, J. P.; Zoerb, M. C.; Hill, A. D.; Harris, C. B. Ultrafast observation of a solvent dependent spin state equilibrium in $\mathrm{CpCo}(\mathrm{CO})$. J. Am. Chem. Soc. 2012, $134,3120-3126$.

26. Sawyer, K. R.; Cahoon, J. F. Schanoski, J. E.; Glascoe, E. A.; Kling, M. F.; Schlegel, J. P.; Zoerb, M. C.; Hapke, M.; Hartwig, J. F.; Webster, C. E.; Harris, C. B. Time-resolved IR Studies on the Mechanism for the Functionalization of Primary $\mathrm{C}-\mathrm{H}$ Bonds by Photoactivated Cp*W(CO) $)_{3}(\mathrm{Bpin})$. J. Am. Chem. Soc. 2010, 132, 1848-1859. 